\title{
100 years of the Royal Air Force's contribution to medicine: providing care in the air and delivering care by air
}

\author{
Authors: Bonnie N Posselt, ${ }^{A}$ Andrew M Greenhalgh ${ }^{B}$ and Michael K Almond ${ }^{C}$
}

The Royal Air Force (RAF) came into being during World War I as the world's first independent air force on the 1 April 1918, amalgamating elements of the Royal Flying Corps (RFC), itself established in 1912 and the Royal Naval Air Service which had formally separated from the Admiralty's administered Air Wing of the RFC in 1915. The RAF therefore celebrates its 100th anniversary in the same year that the Royal College of Physicians of London celebrates its 500th. This article will cover the contribution that military aviation has made to medicine since 1913 with the emphasis of three examples focusing on delivering care by air, providing care in the air and in developing systems for supporting aircrew or patients at the extremes of physiological stress.

KEYWORDS: Royal Air Force, aeromedical evacuation, aviation Medicine, oxygen systems, dialysis

\section{Aeromedical evacuation}

The first two decades of the 21st century have seen the RAF and medicine become almost synonymous in most people's mind with Medical Emergency Response Teams (MERT) providing frontline trauma care and casualty retrieval by helicopter in Afghanistan and Iraq and Critical Care Air Support Teams (CCAST), providing the safe transfer of critically ill patients over long distances in an intensive care setting using large multi-engined aircraft usually back to the UK. It may surprise many to know the first British fusion of aviation and medical care dates from 1913, just 10 years after the first successful powered flight. Samuel Franklin Cody, the designer of the British Army Aeroplane No 1 converted his later aircraft, the Cody VI, into a flying ambulance. The aeroplane could carry three medical staff (hospital orderlies) and was equipped with a stretcher, operating table and all the supplies necessary for medical emergencies (Fig 1).

Cody's 'air-ambulance' was not adopted by the military and Cody died that same year in an air accident. World War I

Authors: ${ }^{\mathrm{A}}$ specialty registrar, Royal Air Force, Centre of Aviation Medicine, RAF Henlow, Bedfordshire, UK; ${ }^{\text {B }}$ core trainee (acute medicine), RAF Medical Services, Royal Infirmary of Edinburgh, Edinburgh, UK; C Consultant, Royal Air Force, Aviation Medical Clinical Services, RAF Henlow, Bedfordshire, UK

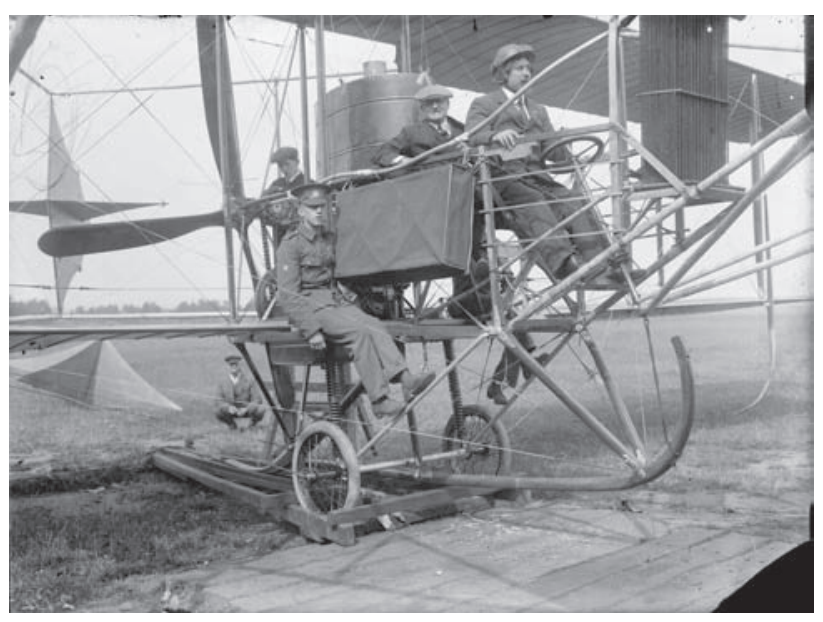

Fig 1. Samuel Cody at the controls of Cody Aircraft Mark VIA demonstrating its potential as an ambulance plane to the British Army. Reproduced with permission from the Imperial War Museum (c) IWM.

commenced the following year which not surprisingly directed the attention of aircraft development towards their use in combat and observation roles.

It was in the latter role that the Royal Flying Corps (RFC) became involved in the first aeromedical evacuation (as distinct from a combat rescue). In February 1917 an observation aircraft, a Royal Aircraft Factory B.E.2c, was supporting elements of the Imperial Camel Corps advancing into the Sinai, then held by Turkish forces, near Bir-el-Hassana. A Bedouin, who fought for both sides during the war, shot Lance Corporal MacGregor, wounding him in the ankle. The observation aircraft cooperating with the advance had landed and the battalion medical officer persuaded the pilot to take the casualty in the aircraft's observer's seat, his ankle supported by a box splint. Travelling by air to the hospital, which had been established near the coast, took just 45 minutes instead of the 3 days if transported by camel, 'and thus the casualties life was saved', as it was reported at the time. Unfortunately neither the name of the medical officer nor the pilot is recorded. ${ }^{1}$

Immediately after World War I Great Britain continued with a long-running conflict in what was then known as British Somaliland, now Somalia. The RAF expedition sent to support this action, Zed Force, had as its medical officer Wing Commander 
William Tyrrell MC DSO* (later Air Vice Marshal). In 1920 he set up the first organised aeromedical service utilising a purposefully adapted aircraft, a DeHavilland DH9 biplane, which had a coffinlike structure fitted above the fuselage to accommodate a patient in a stretcher. Increasingly, those moved by air included patients with non-combat injuries and medical patients rendered ill by disease or the harsh environment. ${ }^{2}$

Up to this point the aircraft used for patient movement were not designed with the patient or aeromedical care in flight in mind. To correct this deficiency the RAF adapted two of its first purposebuilt troop carriers to accommodate patients, including those on stretchers. Equipment for personal hygiene was provided and in-flight care delivered by two onboard medical staff, this was the Vickers Vernon. The first of such aircraft came into service in Iraq in 1922. It even had facility to load stretcher patients through the nose directly into the aircraft using rails. ${ }^{3}$

From these first movements by air of the injured and ill by the military the RAF demonstrated the safety and efficiency of the process. This was soon adopted for civilian use, initially by the embryonic Royal Australian Flying Doctor Service and then in 1933 Captain EE Fresson, who had formed Highland Airways Limited, started the UK's first civilian aeromedical service from Kirkwall in the Orkney Islands.

From these early uses we now have the routine and extensive networks of emergency helicopter and aeromedical transport services, both charitable and private, transferring critically ill patients, repatriation services and for those needing routine outpatient services across the UK. The RAF continues to offer the highly specialist service of the Air Transportable Isolator to move patients with highly infectious diseases, most recently seen in the Ebola crisis in West Africa 2013-6.

\section{The role of medical officers in developing oxygen delivery systems}

Over the past 100 years aircraft oxygen systems have evolved significantly from simple bottled oxygen delivered via a pipe held in the mouth, to complex molecular oxygen sieves that generate oxygen rich air usually by extracting it from the engine air. Today, in addition to providing oxygen, a breathing system can also regulate the flow and volume of oxygen dependant on the need of the user, with minimum resistance, protect against lung collapse under acceleration, deliver positive pressure breathing, protect the respiratory tract from fire, fumes and even potentially exclude nuclear particles. Doctors working within the RAF in the specialty of aviation medicine have played a vital role in researching the physiological effects of the flying environment and have developed procedures and equipment to protect aircrew from these harmful effects. They often tested new equipment on themselves, sometimes at great risk, which is pleasingly no longer demanded.

The deleterious and incapacitating effects of hypoxia with ascent to altitudes greater than 10,000 ft were first documented in the 18th century with hot air balloons and supplementary oxygen was carried in rudimentary leather sacks for such flights. Initial powered flights between 1903 and 1914, being only short in duration and limited to a few hundred feet, did not encounter this problem and on-board oxygen was not required. World War I saw the increasing use of aircraft at altitude, with early oxygen systems only comprising of a rubber tube that was gripped between the teeth providing a continuous flow of oxygen from a bottled source

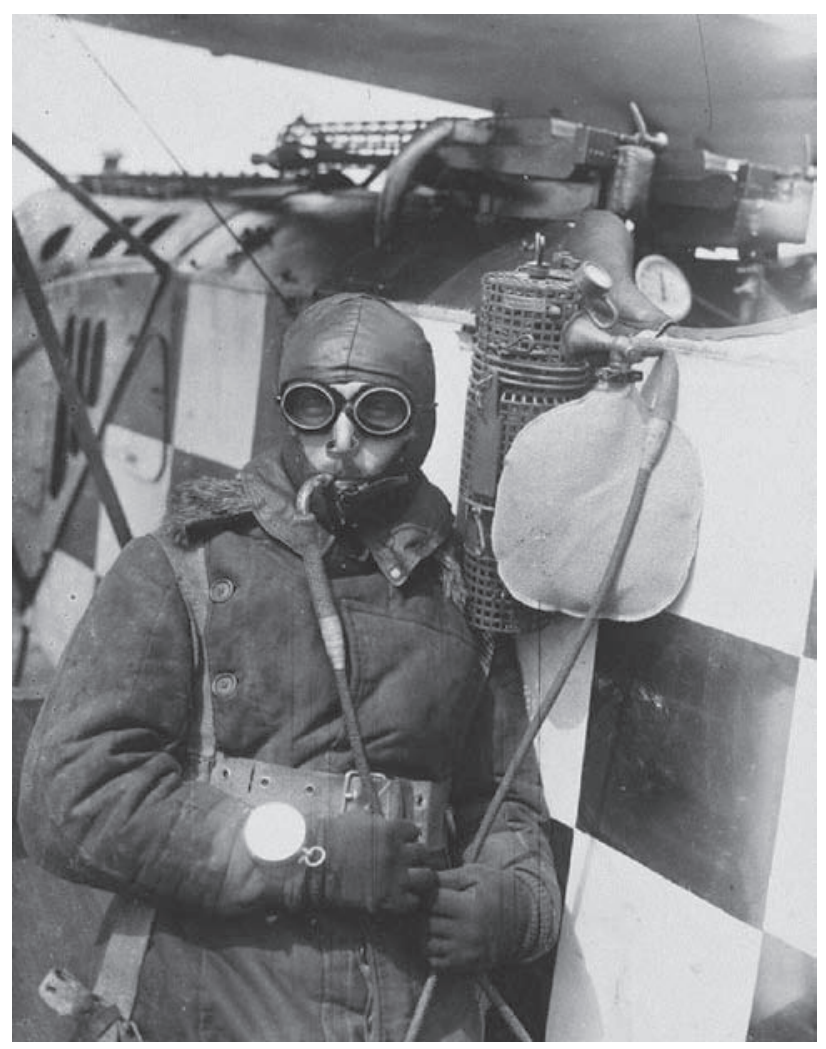

Fig 2. Continuous flow oxygen delivered by a tube held in the mouth. Reproduced with permission from the Farnborough Air Sciences Trust (FAST) archive.

(Fig 2). The principle flaw to this system was that you could only breathe through the mouth and it became difficult to grip on long sorties in the freezing conditions of an open cockpit. From these problems identified, this system was adapted to incorporate the tube into a rubber mask (Fig 3). Increasing flow settings were able to be manually controlled so that it could provide sufficient (100\%) oxygen up to $29,750 \mathrm{ft}^{4}{ }^{4}$ However, flow could still be impaired as moist expired air would commonly freeze with the cold temperatures experienced at these altitudes. Despite their flaws, generally it was accepted that supplementary oxygen was necessary and by 1918 , all aircrew were issued with oxygen masks for use in flight.

After the war, research budgets and allocated resources were cut to a minimum, but progress was still able to continue with the formation of the Flying Personnel Research Committee (FPRC), set up to guide military command and inform decisions made on all aspects of flying. From these humble beginnings, the RAF physiology laboratory was formed in 1939 and the Institute of Aviation Medicine at Farnborough in 1945. These organisations now had facilities such as the hypobaric chamber and specifically allocated and modified aircraft in which trials and research could be conducted to develop useable oxygen systems that would meet the demands of the flying environment. Additionally, some medical officers were qualified pilots, able to undertake the flight trials themselves.

Some of the greatest contributions from the aviation medicine cadre involved measuring the respiratory patterns and demands placed on aircrew in the activities of various phases of flight and defining what the desired acceptable requirements for a 


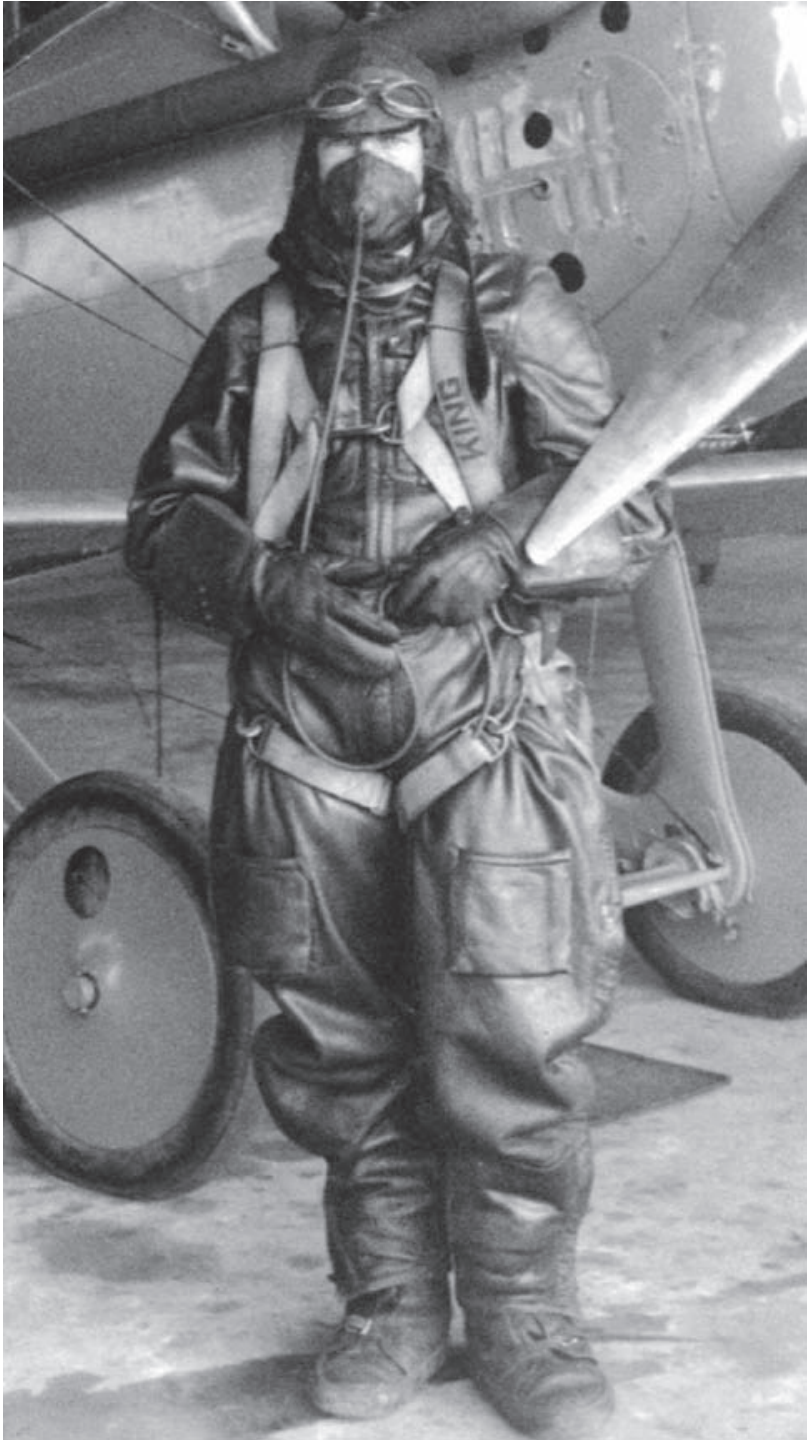

Fig 3. Continuous flow oxygen delivered by a tube inserted into a face mask. Reproduced with permission from the Farnborough Air Sciences Trust (FAST) archive

breathing system are. ${ }^{5}$ The most pressing priority was to address the wasteful nature of using continuous flow oxygen. In such systems oxygen is only effectively being used during phases of inhalation; therefore, aircraft were carrying far more oxygen than was actually required. From identifying these flaws the aviation medicine team developed an oxygen economiser, nicknamed the 'Puffing Billy'. With this system, the flow of oxygen was controlled by a regulator and stored in a flexible rubberised bag which then delivered oxygen only when the subject inhaled. The weight saved by using this system was significant, with a $500 \mathrm{lb}$ reduction reported in a multi-crewed Wellington aircraft. ${ }^{4}$ Historically, the face mask delivering oxygen was loose fitting, with the Puffing Billy a better fitting oxygen mask was developed with a separate expiratory valve, the Type E mask. Further small modifications have been made in the subsequent iteration of masks, the $P$ mask being designed with a toggle which can increase tension on the face, enabling it to be used for positive pressure breathing, which is

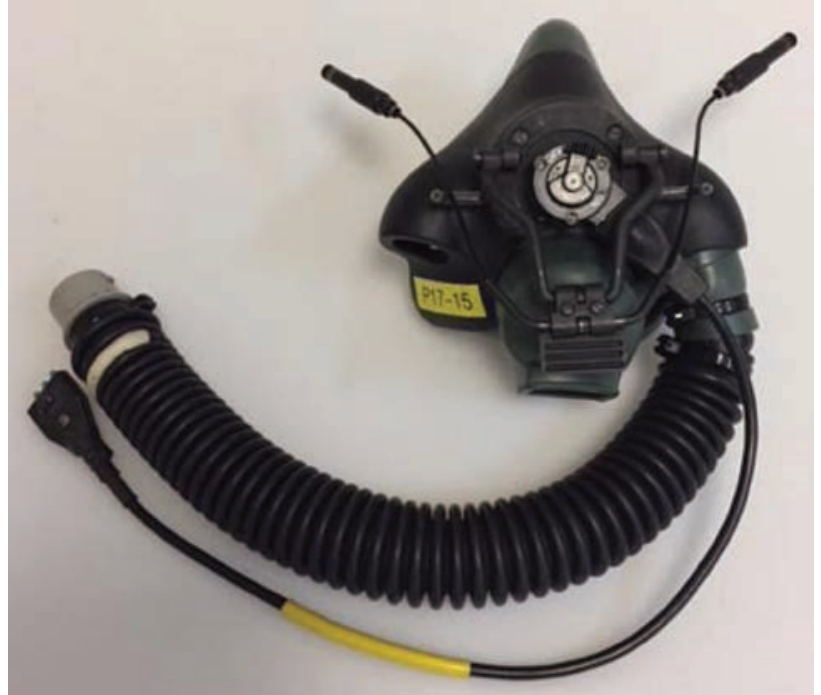

Fig 4. P/Q mask. Photo taken at RAF Centre of Aviation Medicine by Bonnie Posselt and reproduced with permission.

required when breathing oxygen at altitudes above 40,000 ft. The P mask was brought into service in the late 1950s, with the Type Q mask as a smaller version, both are still in use today (Fig 4$).^{6}$ Initially, oxygen systems were part of the aircraft structure with the regulator being panel mounted. Subsequently they became man-mounted to provide continued protection from hypoxia in the event of egress from the aircraft.

As has been described, doctors working in the specialised field of aviation medicine have made significant and direct contributions to the development of improved oxygen systems in the aviation environment. It is not just military aircraft that have benefited from their expertise, with the developments and knowledge being applied to civil aircraft, climbers and gliders. The knowledge gained in developing the systems to deliver oxygen to aircrew has had a direct benefit to those developing analogous systems for use in hospital, the domiciliary setting and in portable systems for patient use.

\section{The contribution of the RAF to dialysis services in Great Britain}

Military medicine often yields great innovation with applications that spread beyond the treatment of service personnel. One such innovation was the advent of modern renal dialysis which can be partly attributed to the role played by the RAF in adopting this emerging technology during the 1950s.

Many servicemen who were treated during World War II benefitted from improved surgical techniques and other developments of the era only to die from subsequent renal failure. The need for an artificial kidney was given great priority by service chiefs who were impressed by the results of dialysis on casualties in the Korean War (1950-3). ${ }^{7}$

Major Paul Teschan of the US Army Medical Corps first demonstrated the use of the Boston-modified version of Kolff's rotating drum dialysis machine in Korea and demonstrated a reduction in mortality from $87 \%$ to $53 \%$ in those patients treated for what was then called 'acute renal failure' (ARF) and who received care in a specialist renal unit. ${ }^{8-10}$ This demonstration resulted in the appointment of Ralph Jackson to establish a renal 
failure unit to support British Forces around the world at the Princess Mary's Hospital, RAF Halton.

Princess Mary's Hospital, RAF Halton, was opened formally in 1927 and played a large role in World War II. By 1945 it had treated approximately 20,000 war casualties. The hospital developed an international reputation for its innovation in medical science and surgical techniques. In 1940, it became the first hospital to use penicillin on a large scale, soon after its discovery and introduction into clinical medicine by Flemming, Florey and Chain. ${ }^{11,12}$ It was therefore chosen as the site for the Royal Air Force Renal Unit in 1956, the second of its kind to be opened in the UK (after Leeds General Infirmary in 1955).

Group Captain (later Air Vice-Marshal Sir) Ralph Jackson oversaw the use of the Kolff Twin Coil Dialysis machine - the first of its kind in the UK. This was the machine of choice as it was the lightest and most easily adaptable for transportation by road or, importantly, by air which had been a stipulation at the unit's inception. Jackson was aided by Dr AM (Jo) Joekes, who was appointed civilian consultant of the unit. Joekes had been involved in establishing the first renal unit in Hammersmith Hospital in 1946 and as a relative of Willem Kolff had been aware of the potential of his artificial kidney at an early stage. ${ }^{7}$

Jackson first presented his experiences with the Twin Coil to the Royal Society of Medicine in 1958 at which point he had dialysed 27 patients: 21 with acute renal failure, four cases of chronic renal failure and two cases of acute poisoning. One patient had been successfully dialysed remote from the unit. In his presentation were detailed the unit's outcomes and Jackson's early impressions of the Twin Coil. He advocated early referral to a renal unit in the event of acute renal failure, but that the artificial kidney played only a small role in the management of the condition and was no substitute for effective medical management. ${ }^{13}$

The initial findings were followed up in 1960 with a case series of 80 patients in the British Medical Journal. ${ }^{14}$ The publication of this paper in conjunction with visits of clinicians to the Halton unit resulted in the creation of other renal units throughout the UK, nearly all of which employed or went on to employ the Twin Coil. ${ }^{7}$

The design of the initial machine was improved upon with the help of an RAF technical unit that developed better electronic monitoring and more efficient blood pumping. These improvements alongside the demonstration that the artificial kidney could be used in the treatment of chronic renal failure resulted in long-term renal dialysis becoming adopted within the UK. Furthermore, Joekes developed a safer technique for renal biopsy which, with the use of an electron microscope bought for the RAF Institute of Pathology and Tropical Medicine in the early 1970s, allowed for more accurate diagnoses and targeted treatment. ${ }^{7}$

Further advances were made to refine the practice of haemodialysis and many distinguished careers began in Halton which later opened 'The Sir Ralph Jackson Acute Renal Intensive Care Unit'. The skills acquired by Halton's physicians led them to demonstrate that arteriovenous haemofiltration could be performed in flight and published a case study of two successful aeromedical evacuations, one on a 14-hour flight from the Falkland Islands, in 1986 thus setting the scene for the future inflight complex care of CCAST. ${ }^{15}$
In 1995, the unit was closed as part of the reorganisation of defence medicine and the chronic renal failure programme transferred to Oxford. The techniques that were developed at Princess Mary's Hospital, RAF Halton inform today's use of deployed renal replacement therapy. This has most recently been utilised in the deployed operational environment during the conflict in Afghanistan in which continuous venovenous haemofiltration (CVVH) was employed in the management of polytrauma patients in intensive care. ${ }^{16}$

\section{References}

1 Dolev $\mathrm{E}$. The first recorded aeromedical evacuation in the British Army - The true story. J R Army Med Corps 1986;132:34-6.

2 Scholl MD, Geshekter CL. The Zed expedition: the world's first air ambulance? J R Soc Med 1989;8:679-80.

3 Rankin RH. Sky Hospital. Flying and Popular Aviation. Vol XX1X (2). Chicago, USA: Ziff-Davis, 1941.

4 Rood G. A brief history of flying clothing. Journal of Aeronautical History 2014: Paper No 2014/01.

5 Macmillan A. Development of breathing systems - contributions of flight research and flight trials. Royal Air Force Historical Society Journal 43 2008:54-66.

6 Gibson TM, Harrison MH. Into Thin Air: a history of aviation medicine in the RAF. London: Robert Hale, 1984.

7 Hopewell J. Early history of the treatment of renal failure by haemodialysis and transplantation - UK. www.renhist.co.uk/ historydialtrp.html [Accessed 8 Feb 2018].

8 Turner N. The Korean War 1950-3: acute dialysis finds its place. http://historyofnephrology.blogspot.co.uk/2011/01/koreanwar-1950-3.html?view=timeslide [Accessed 2 February 2018]

9 Teschan PE. Haemodialysis in military casualties. ASAIO J 1955:1:52-4.

10 Smith LH, Post RS, Teschan PE et al. Post-traumatic renal insufficiency in military casualties. II. Management, use of an artificial kidney, prognosis. Am J Med 1955;18:187-98.

11 Lax E. The mold in Dr Florey's coat: The story of the penicillin miracle. New York: Henry Holt and Company, 2005.

12 RAF Halton Heritage - Princess Mary's Hospital. www.raf.mod.uk/ rafhalton/aboutus/princessmaryshospital.cfm [Accessed 1 February 2018].

13 Jackson RC. Experiences with the Kolff Twin Coil artificial kidney at the renal unit, Princess Mary's Royal Air Force Hospital, Halton. Proc R Soc Med 1958;51:1071-2.

14 Jackson RC, Bunker NVD, Elder W], Joekes AM. Treatment of renal failure in a unit with facilities for haemodialysis (Twin-Coil artificial kidney). Br Med J 1960;2:1909-16.

15 Stevens PE, Bloodworth LL, Rainford DJ. High altitude haemofiltration. Br Med J (Clin Res Ed) 1986;292:1354.

16 Nesbitt I, Almond MK, Freshwater DA. Renal replacement in the deployed setting. J R Army Med Corps 2011;157:179-81.

Address for correspondence: Dr Mike K Almond, Royal Air Force, Aviation Medical Clinical Service, RAF Henlow, Bedfordshire SG16 6DN, UK. Email: mike.almond1@gmail.com 